\title{
Morphological Effects of Brefeldin A on the Intracellular Transport of Secretory Materials in Parotid Acinar Cells
}

\author{
Shohei Yamashina ${ }^{1}$, Osamu Katsumata ${ }^{1}$, Hideaki Tamaki ${ }^{1}$, and Akira Takatsuki ${ }^{2}$ \\ ${ }^{1}$ Department of Anatomy, Kitasato University School of Medicine, Sagamihara 228 and ${ }^{2}$ Department of Micro- \\ biology, Faculty of Agricultural Chemistry, University of Tokyo, Bunkyo-ku, Tokyo 113, Japan
}

Key words: Golgi complex/Brefeldin A/parotid gland/secretion/electron microscopy

\begin{abstract}
The morphological effects of Brefeldin A (BFA) on the parotid acinar cells of a rat were investigated at the stage of active resynthesis of secretory materials following administration of the secretogogue, isoproterenol. Incubation with BFA resulted in: a) marked dilation of the rough endoplasmic reticulum (RER), b) involution of the Golgi complex to rudimentary forms which disseminated throughout the cytoplasm, and c) agenesis of secretion granules. It appears that the primary action of BFA is inhibition of the export of secretory materials from the RER toward the Golgi complexes. Histochemical staining indicated the thiamine pyrophosphatase (TPPase) positive saccules of the Golgi stack to undergo degradation in autophagic vacuoles. In contrast, small vesicles showing the osmium reducing activity characteristic of cis elements, including osmium negative vesicles, continued to be present throughout a 4-h period of investigation, indicating the cis and, most likely, medial elements to be the components of the rudimentary Golgi complexes. On removal of the drug, a large number of transport vesicles appeared immediately from the RER and carried secretory materials to the rudimentary Golgi complex, so that the organelles were rapidly reconstructed within 30-60 min, followed by the reaccumulation of secretory granules by $90 \mathrm{~min}$. It is thus indicated that the size and configuration of the Golgi complex is regulated by a dynamic equilibrium of the transport of secretory materials, and that the rudimentary Golgi complex containing cis and probably medial elements may function as the smallest units of the Golgi complex for full development as seen under normal conditions.
\end{abstract}

The common pathway of secretory proteins from the rough endoplasmic reticulum (RER) to the extracellular milieu through the Golgi complex and secretory granules has been well documented $(3,6,22)$. The controlling mechanism of protein transport is, however, one of the most basic issues to be elucidated in cell biology, since its clarification may lead to a better understanding of the fundamental cellular functions.

Brefeldin A (BFA), a metabolite of a soil fungus (11), was initially recognized as an inhibitor of virus multiplication (26). Takatsuki and Tamura (25) found BFA to arrest the transport of the G-protein of the vesicular stomatitis virus at a point in front of or within the Golgi apparatus in BHK-21 cells. Similar blocking of exportable proteins by the drug has been observed in cultured hepatocytes $(9,19,21)$, mouse pituitary cells $(18), \mathrm{T}$ lymphocytes (15), and Chinese hamster ovary (CHO) cells (5).

Acinar cells of the parotid gland, as well-developed exocrine glandular cells, have differentiated for the extensive synthesis and secretion of digestive enzymes. Their secretory processes, induced by a single injection of isoproterenol (IPR), a $\beta$-adrenergic agonist, have been well characterized $(1,4,14)$. In the present study, we examined the effects of BFA on parotid acinar cells at a particular stage of extensive protein resynthesis following secretory stimulation by IPR. Special attention was directed to structural and histochemical changes in the Golgi complex.

\section{MATERIALS AND METHODS}

Male Wistar-Imamichi rats weighing $200-250 \mathrm{~g}$ were intraperitoneally administered freshly prepared IPR at a dose of $2 \mathrm{mg} / 100 \mathrm{~g}$ body weight. One $\mathrm{h}$ later, the parotid glands were excised quickly under light anesthesia with ether; the lymph nodes were removed, and dissected into small pieces of lobules with the aid of a dissecting microscope. These pieces were incubated for as long as $4 \mathrm{~h}$ in Hanks balanced salt solution at $37^{\circ} \mathrm{C}$ with continuous oscillation in a water bath incubator. BFA was isolated in crystalline form from FL-24 fungi according to Tamura et al. (26). A stock solution of BFA was prepared by dissolving $2 \mathrm{mg}$ BFA in $1 \mathrm{ml}$ methanol. BFA was included in the incubation solution at a final concentration of $2.5 \mu \mathrm{g} / \mathrm{ml}$. At a specified time, some of the tissue fragments were fixed in $2.5 \%$ glutaraldehyde for $1 \mathrm{~h}$ followed 
by post-fixation for $1 \mathrm{~h}$ at $4^{\circ} \mathrm{C}$ in a $1: 1$ mixture of $2 \%$ aqueous osmium tetroxide and $3 \%$ aqueous potassium ferrocyanide (13). They were then processed for conventional electron microscopy. To examine the recovery from the effects of BFA, parotid fragments excised from a rat $1 \mathrm{~h}$ after IPR administration were incubated for $2 \mathrm{~h}$ with $2.5 \mu \mathrm{g} / \mathrm{ml}$ BFA, transfered into fresh medium containing no BFA, and incubation was continued. Some tissue fragments removed at a specified time were prepared for electron microscopy as described above. To demonstrate histochemically thiamine pyrophosphatase (TPPase), $40-\mu \mathrm{m}$-thick sections of glutaraldehyde fixed tissues cut on a microslicer (Dosaka EM, Co. Ltd., Kyoto, Japan) were incubated in the medium for TPPase using cerium chloride as a capture agent (2) for $30 \mathrm{~min}$ at $37^{\circ} \mathrm{C}$ followed by postfixation in the mixture of osmium tetroxide and potassium ferrocyanide. Osmium impregnation was performed according to the method of Friend and Murray (8). Ultrathin sections cut on an LKB ultramicrotome were stained with uranyl acetate and lead citrate, and observed by a JEM-1200EX electron microscope (JEOL, Ltd., Tokyo, Japan).

\section{RESULTS}

Morphological effects of BFA. In the parotid acinar cells of a rat injected with IPR $1 \mathrm{~h}$ before sacrifice, secretory granules were completely depleted, and in the cytoplasm, well-developed stacks of rough endoplasmic reticulum (RER) and Golgi complexes were abundantly present. Each Golgi complex had formed an elaborate, continuous, and reticulated organelle in the supranuclear area. Numerous small vesicles could be seen surrounding each Golgi stack. During in vitro incubation of the tissue fragments, secretory granules started to appear $1 \mathrm{~h}$ following in vitro incubation, and subsequently accumulated gradually in the luminal cytoplasm during $4 \mathrm{~h}$ of incubation (Fig. 1). Budding of transport vesicles from the RER was quite apparent in the vicinity of the Golgi complex.

The morphology within the parotid acinar cells changed remarkably after incubation with $2.5 \mu \mathrm{g} / \mathrm{ml} \mathrm{BFA}$, the effects of which continued for as long as $4 \mathrm{~h}$. The RER cisternae became swollen at their peripheries within $1 \mathrm{~h}$ following BFA treatment, and the stacks became irregularly arranged. Cisternal spaces dilated progressively with the time of incubation with BFA (Fig. 2 ), and huge canals or distended vacuoles of the RER, became distributed throughout the cytoplasm surrounding the nucleus $4 \mathrm{~h}$ after adding BFA. The swollen cisternal spaces contained flocculent materials.

The most obvious effect of BFA was the great change it caused in the size and shape of the Golgi complex (Figs. 3, 4, 5). No definite stacks of Golgi cisternae could be detected, and aggregated small vesicles distributed among dilated RER appeared as cut profiles of complicated small tubular anastomoses (Fig. 4). Atypical features made it difficult to identify these structures as those of the Golgi complex. However, as discussed below, the histochemically demonstrated osmium reducing activity indicated that these structures were characteristic of the Golgi complex, and were in rudimentary form. Since rudimentary Golgi apparatus was disseminated in narrow spaces between dilated cisternae of the RER, it would appear that BFA causes fragmentation of Golgi complexes. Several groups of aggregated small vesicles or rudimental Golgi apparatus were always present throughout the acinar cells during the $4 \mathrm{~h}$ following BFA addition (arrows in Fig. 2). Transport vesicles showed no apparent association with rudimentary Golgi complexes. In no case could any secretory granules be found, indicating that BFA had completely inhibited their formation.

Histochemical changes. The histochemical staining of TPPase indicated the presence of reaction products in one or two of the trans-most cisternae of well-developed Golgi complexes of acinar cells incubated without BFA (Fig. 1). BFA caused extensive changes in TPPase distribution in the Golgi complexes. One $h$ following BFA treatment, the TPPase-positive trans cisternae of a Golgi complex reduced in size could be seen, but large vacuoles, occasionally containing lamellar inclusions, appeared in close proximity to the TPPase-positive cisternae (Fig. 3). The approach of primary lysosomes in the area was also evident. The deformation of TPPase-positive cisternae was noted infrequently. Two $h$ after BFA treatment and thereafter, TPPase reaction products ceased to be associated with the reduced elements of Golgi complexes. Autophagic vacuoles, however, occasionally showed reaction products due to TPPase activity. But $4 \mathrm{~h}$ following incubation with BFA, reaction products were no longer evident.

Osmium impregnation indicated dark deposits of a heavy metal in one to three of the cis-most cisternae and in cis-associated vesicles of Golgi complexes in acinar

Fig. 1. Electron micrograph of a parotid acinar cell incubated for $2 \mathrm{~h}$ without BFA. A rat was administered IPR. One $\mathrm{h}$ following secretory stimulation, the parotid gland was removed, and tissue fragments were incubated without BFA. The section was treated for the histochemical demonstration of TPPase. Well-developed rough ER and Golgi complex can be seen, and trans elements of the Golgi cisterna show reaction products for TPPase activity. A few secretion granules can be recognized in the luminal cytoplasm, indicating that the reformation of secretory granules has started at this stage. $\times 21,000$. Scales in the micrographs indicate $1 \mu \mathrm{m}$.

Fig. 2. Electron micrograph of a parotid acinar cell treated with BFA for $2 \mathrm{~h}$. Secretion was stimulated as in Fig. 1, and parotid tissue fragments were incubated with BFA. A large part of the cytoplasm is occupied by extensively dilated RER. Clusters of small vesicles (indicated by arrows) are disseminated throughout the cytoplasm. There is no indication that secretory granules have formed anew. $\times 10,000$. 
Effects of Brefeldin A on Partoid Acinar Cells
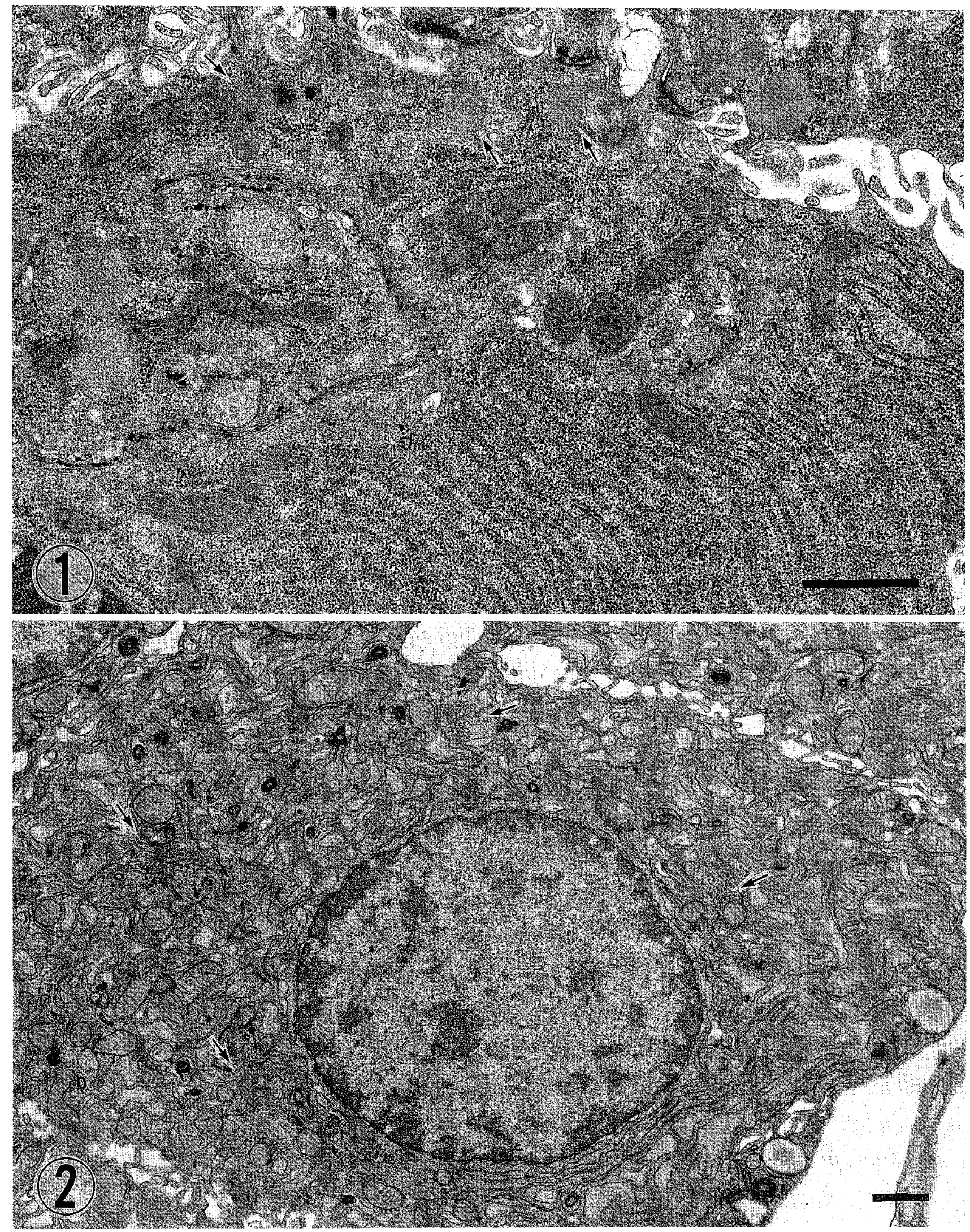


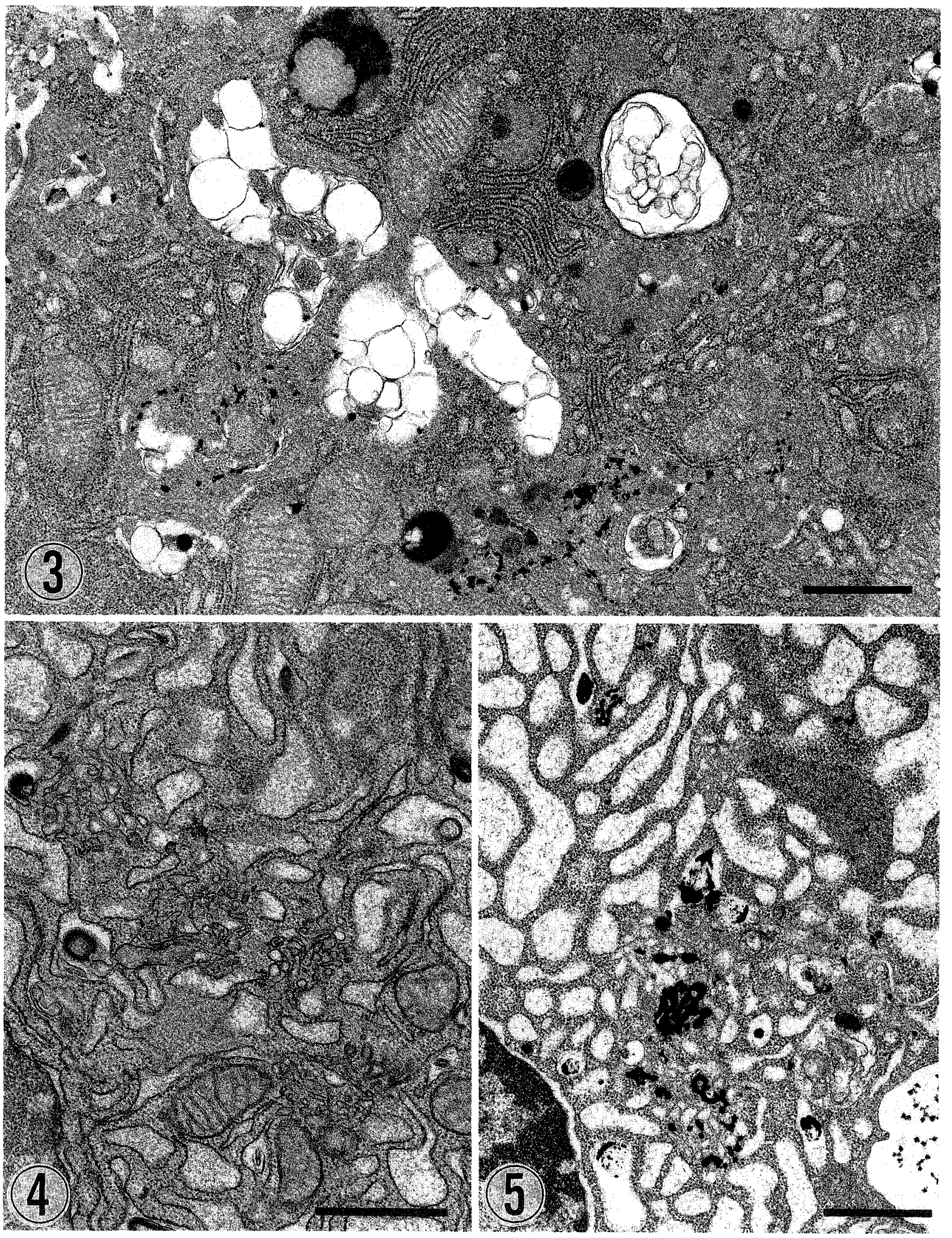


cells not treated with BFA. The inner membranes of mitochondria were sometimes blackened by this process. In sections of parotid acinar cells incubated for $1 \mathrm{~h}$ with BFA, osmium deposits were evident in the cisternae and small vesicles located at the cis face of diminishing Golgi complexes that had already decreased in size. Among the osmium positive vesicles, osmium negative vesicles, most likely components of medial cisternae, were present. Osmium deposits continued to remain in the aggregated vesicles during the $4 \mathrm{~h}$ following BFA treatment (Fig. 5). Thus, the characteristics of cis and medial elements of Golgi complexes are possibly retained in rudimental form.

Recovery from BFA. The regression of swollen RER was quite evident immediately following removal of BFA from the incubation medium, and tight stacks of normal RER were recovered by $2 \mathrm{~h}$ after this removal. During the process of recovery, a large number of transport vesicles was seen in the vicinity of the rudimental Golgi complexes. The reconstruction of stacked cisternae appeareri to take place as a result of adding transport vesicles to branched tubules, and rapi 1 recovery and regeneration of Golgi stacks were evident as early as $15 \mathrm{~min}$ following removal of the drug (Fig. 6). Hypertrophy of stacks and cisternae of Golgi was noted at $30 \mathrm{~min}$. In the trans region of the Golgi, various numbers of pale vacuoles were present, indicating immature secretory granule formation. However, at this time TPPase activity could not be detected in the regenerating Golgi stacks. Fully mature secretory granules in the apical cytoplasm could be seen to have accumulated at $90 \mathrm{~min}$ after drug removal. At this time, TPPase activity was evident in one or two of the transmost cisternae of the Golgi stacks, and the acinar cells could no longer be distinguished from those of the control (Fig. 7).

\section{DISCUSSION}

The effects of BFA on parotid acinar cell morphology are the following: a) extensive dilation of the RER cisternal spaces, b) remarkable reduction in Golgi complex size, and c) the complete inhibition of secretory granule formation. These changes were fully reversible, and recovery to normal conditions was immediate on removal of the drug from the medium.
This drug has little or no effect on the rate of protein synthesis $(18,19,25)$, and no transport vesicles have been found in the vicinity of the Golgi complexes. Thus, dilation of the RER cisternae may possibly be due to the inhibitory effect of BFA on the transport of secretory proteins from the RER to Golgi complexes, resulting in the abnormal accumulation of secretory proteins in the RER. Although the exact mechanism for the action of this drug still remains to be clarified, the interaction of BFA with ER membranes to bring about changes of unknown cause and the subsequent complete inhibition of transport vesicle formation is a distinct possibility. Similar pharmacological activity of BFA has been observed in cultured hepatocytes $(9,19)$, mouse pituitary cells (18), T-lymphocytes (15), and $\mathrm{CHO}$ cells (5).

Golgi complex size under normal conditions must be maintained by having the amounts of materials leaving the Golgi kept the same as those entering it $(10,20)$. The observed decrease in the size of the Golgi complex is quite likely the result of inhibition of the entry of secretory proteins from the RER, while their departure from the trans region of the Golgi is little affected. Upon blocking of the entry of materials, trans cisternae possessing TPPase activity appeared to change into autophagosomes, which may undergo degradation by lysosomal enzymes. Cis elements with osmium reducing activity, however, as well as some medial cisternae, remain in the rudimental form of vesicular aggregation.

Rapid redistribution in the RER of cis and medial Golgi proteins in T-lymphocyte (15) and CHO cells (5) was shown to occur following treatment with BFA. Although such redistribution was not determined in parotid acinar cells following IPR treatment, it should be emphasized that some, though not necessarily all, cis and, probably, medial elements continue to remain in the rudimentary form of Golgi complexes throughout the period of examination, and that they apparently become special sites for Golgi complex reconstruction at the stage of recovery.

Inhibition of the departure of materials from the RER has been observed under various conditions such as low temperature $(23,24,27)$ and inhibition of ATP production $(12,27)$. According to Featherstone et al. (7), the transport of newly synthesised G-protein of the vesicular stomatitis virus to the Golgi complexes from

Fig. 3. Changes in a Golgi complex due to BFA during $1 \mathrm{~h}$ incubation. The section was treated for the histochemical demonstration of TPPase. The Golgi stacks are reduced in size and deformed. Autophagic vacuoles and lysosomes can be seen closely associated with the Golgi complex. Reaction products of TPPase are evident in the Golgi stack, which continued to be present for $1 \mathrm{~h}$ after BFA treatment. However, a rudimentary Golgi complex without cisternal stack failed to show any positive reaction. $\times 20,000$.

Fig. 4. High power view of a rudimentary Golgi complex after $2 \mathrm{~h}$ of incubation with BFA. An aggregation of small vesicles and thin tubules can be seen within it. Note the dilated cisternal spaces of the RER and the absence of transport vesicles. $\quad \times 23,400$.

Fig. 5. Acinar cell incubated with BFA for $4 \mathrm{~h}$ followed by osmium immpregnation. Cisternal dilation has advanced beyond that in Figs. 2 and 4. Dark deposits of osmium are apparent in the aggregation of vesicles, indicating that the clusters are cis elements of the Golgi complex. Vesicles freed from osmium are apparent in the cluster. $\times 19,200$. 

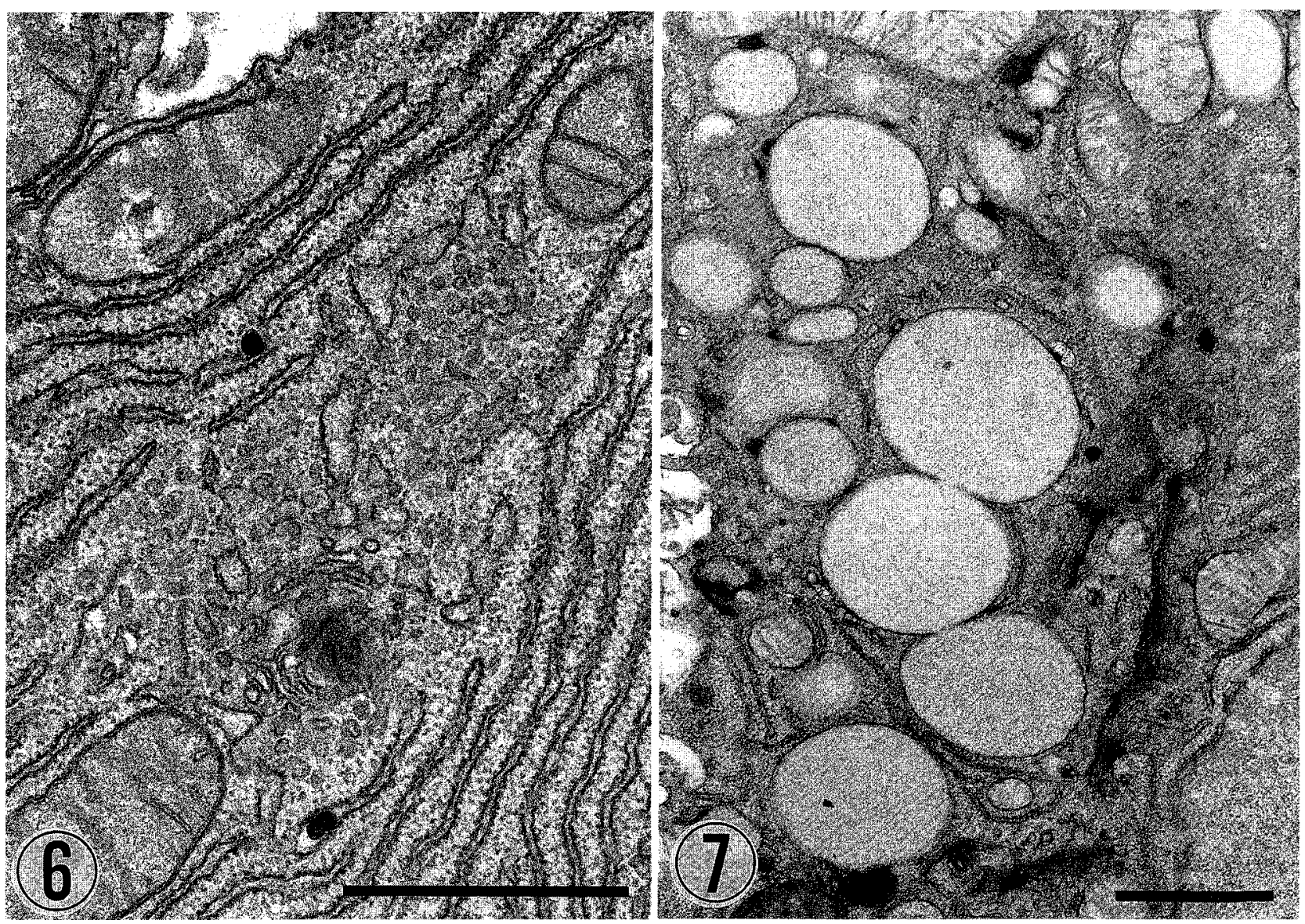

Fig. 6. Fifteen min following removal of BFA. A rat was injected with IPR to stimulate secretion. One $h$ later, parotid fragments were incubated with BFA. At $2 \mathrm{~h}$ of in vitro incubation, the medium was replaced with fresh medium without BFA to assess recovery from BFA effects. Immediately following drug removal, a large number of transport vesicle groups appeared, seeming to form lamellae in close proximity to the rudimental Golgi complex. $\times 37,100$.

Fig. 7. Ninety min after removal of BFA. TPPase histochemistry was assessed. A stack of Golgi cisternae has already recovered and trans cisternae show positive reaction. In acinar cells where stacked arrays of Golgi cisternae have recovered, the reformation of secretion granules is evident. $\times 20,600$.

the RER is inhibited in mitotic cells. Lucocq and Warren (16) found in the mitotic phase of Hela cells the fragmentation of Golgi elements possessing osmium reducing activity. They noted both TPPase activity and immunoreactivity of galactosyl transferase in vesicular aggregations which they designated as Golgi clusters. However, the former activity was present only to a slight degree; thus they stated that "at least some of these smaller clusters were also found to contain the trans Golgi marker TPPase" (17). The features of Golgi clusters as determined from their photographs were very similar to those resulting from treatment with BFA. In support of their observations, we also noted in mitotic acinar cells of the parotid gland morphological and histochemical changes in Golgi complexes similar to those described above in BFA-treated cells (Tamaki and Yamashina, manuscript in preparation).
From the present observations, it is clear that, even with reduction in Golgi complex size due to blocking of the entry of synthesized proteins from the RER, the components of the Golgi persist as various numbers of small vesicle aggregations distributed in the cytoplasm. It is quite likely that clusters of small vesicles may be the smallest units of Golgi complexes in dividing Hela cells, as suggested by Lucocq, et al. (16). It is of particular interest that regressed Golgi consisting of cis and medial elements become the precursors of development following reentry of secretory proteins immediately after removal of BFA. Even $15 \mathrm{~min}$ following recovery from BFA, transport vesicles reappeared in the regions of Golgi clusters, and vesicle elongation led to the formation of immature Golgi stacks at $60 \mathrm{~min}$ following removal of BFA. The process of Golgi cisternae reassembly could not be determined in detail in the present 
study owing to ambiguous three-dimensional architecture and very rapid reconstruction of cisternal structures. Reaction products from TPPase and secretory granule formation were evident again at $90 \mathrm{~min}$ after drug removal. The biological significance of TPPase in trans cisternae is yet to be understood, but the expression of its activity may be intimately related to granule formation and attainment of normal function.

One interesting aspect of Golgi complexes found in the present study is that their size and configuration may be regulated by dynamic equilibrium of material transport traffic. Also, the smallest units containing cis and medial elements may function as sites for proliferation to attain maximal size when material entry is resumed on a normal scale.

Acknowledgments. The authors express their appreciation to the personnel of the Electron Microscopy Laboratory, Kitasato University School of Medicine, for their technical assistance. This study was supported in part by a grant from the Naito Foundation and by a Grant-in-Aid for General Scientific Research from the Ministry of Education, Science and Culture of Japan.

\section{REFERENCES}

1. Amsterdam, A., Ohad, I., and Schramm, M. (1969). Dynamic changes in the ultrastructure of the acinar cell of the rat parotid gland during the secretory cycle. J. Cell Biol. 41: 753773.

2. ANGermulier, S. and Fahimi, H. (1984). A new cerium-based method for cytochemical localization of thiamine pyrophosphatase in the Golgi complex of rat hepatocytes. Comparison with the lead technique. Histochemistry 80: 107-111.

3. Burgess, T.L. and Kelly, R.B. (1987). Constitutive and regulated secretion of proteins. Ann. Rev. Cell Biol. 3: 243293.

4. Byrt, P. (1966). Secretion and synthesis of amylase in the rat parotid gland after isoprenaline. Nature 211: 1212-1215.

5. Doms, R.W., Russ, G., and Yewdell, J.W. (1989). Brefeldin A redistributes resident and itinerant Golgi proteins to the endoplasmic reticulum. J. Cell Biol. 109: 61-72.

6. Farquhar, M.G. and Palade, G.E. (1981). The Golgi apparatus (complex)-(1954-1981)-from artifact to center stage. J. Cell Biol. 91: 77s-103s.

7. Featherstone, C., Griffiths, G., and Warren, G. (1985). Newly synthesized $G$ protein of vesicular stomatitis virus is not transported to the Golgi complex in mitotic cells. J. Cell Biol. 101: 2036-2046.

8. FrIEND, D.S. and MURRay, M.J. (1965). Osmium impregnation of the Golgi apparatus. Amer. J. Anatomy 117: 135-150.

9. Funiwara, T., Oda, K., Yokota, S., Takatsuki, A., and IKEHARA, Y. (1988). Brefeldin A causes disassembly of the Golgi complex and accumulation of secretory proteins in the endoplasmic reticulum. J. Biol. Chem. 263: 18545-18552.

10. Griffiths, G., Fuller, S.D., Back, R., Hollinshead, M., PFEIFFer, S., and Simons, K. (1989). The dynamic nature of the Golgi complex. J. Cell Biol. 108: 277-297.

11. Harri, E., Loeffler, W., Sigg, H.P., Stahelin, H., and TAMM, CH. (1963). Uber die Isolierung neuer Stoffwechselprodukte aus Penicillinum brefeldianum Dodge. Helv. Chem. A. 46: $1235-1243$.

12. JAmieson, J.D. and PALAdE, G.E. (1968). Intracellular transport of secretory proteins in the pancreatic exocrine cell. IV. Metabolic requirements. J. Cell Biol. 39: 589-693.

13. KARNOVSKY, M.J. (1971). Use of ferrocyanide-reduced osmium tetroxide in electron microscopy. Proc. 11th Meeting, Am. Soc. Cell Biol., New orleans, LA. p. 146 (Abstr. 284).

14. LILliE, J.H. and HAN, S.S. (1973). Secretory protein synthesis in the stimulated rat parotid gland. Temporal dissociation of the maximal response from secretion. J. Cell Biol. 59: 708-721.

15. Lippincott-Schwartz, J., Yuan, L.C., Bonifacino, J.S., and KLAUSNER, R.D. (1989). Rapid redistribution of Golgi proteins into the ER in cells treated with brefeldin A: Evidence for membrane cycling from Golgi to ER. Cell 56: 801-813.

16. LuCoce, J.M. and WARREN, G. (1987). Fragmentation and partitioning of the Golgi apparatus during mitosis in Hela cells. EMBO J. 6: 3239-3246.

17. Lucoce, J.M., Pryde, J.G., Berger, E.G., and Warren, G. (1987). A mitotic form of the Golgi apparatus in Hela cells. $J$. Cell Biol. 104: 865-874.

18. Magner, J.A. and Papagiannes, E. (1988). Blockade by brefeldin $\mathrm{A}$ of intracellular trasnport of secretory proteins in mouse pituitary cells: Effects on the biosynthesis of thyrotropin and free $a$ - subunits. Endocrinology 122: 912-920.

19. Misumi, Y., Misumi, Y., Miki, K., Takatsuki, A., Tamura, G., and Ikehara, Y. (1986). Novel blockade by Brefeldin A of intracellular transport of secretory protiens in cultured rat hepatocytes. J. Biol. Chem. 261: 11398-11403.

20. Morre, D.J. and Ovtracht, L. (1977). Dynamics of the Golgi apparatus: Membrane differentiation and membrane flow. Internat. Rev. Cytol. suppl. 5, 61-188.

21. Oda, K., Hirose, S., Takami, N., Misumi, Y., Takatsuki, A., and IKeHaRA, Y. (1987). Brefeldin A arrests the intracellular transport of a precursor of complement $\mathrm{C} 3$ before its conversion site in rat hepatocytes. FEBS Letters 214: 135-138.

22. PALADE, G. (1975). Intracellular aspects of the process of protein synthesis. Science 189: 347-358.

23. RING, P., BJoRkMan, U., and ЕкhOlm, R. (1986). Effect of cooling on intracellular transport and secretion of thyroglobulin. Cell Tiss. Res. 247: 505-513.

24. Saraste, J., Palade, G.E., and Farquhar, M.G. (1986). Temperature-sensitive steps in the transport of secretory proteins through the Golgi complex in exocrine pancreatic cells. Proc. Nat. Acad. Sci. USA 83: 6425-6429.

25. Takatsuki, A. and Tamura, G. (1985). Brefeldin A, a specific inhibitor of intracellular translocation of vesicular stomatitis virus $\mathrm{G}$ protein: Intracellular accumulation of high-mannose type $\mathrm{G}$ protein and inhibition of its cell surface expression. Agric. Biol. Chem. 49(3): 899-902.

26. Tamura, G., Ando, K., Suzuki, S., Takatsuki, A., and ARIMA, K. (1968). Antiviral activity of brefeldin A and verrucarin A. J. Antibiot. 21: 160-161.

27. TARTAKoff, A.M. (1986). Temperature and energy dependence of secretory protein transport in the exocrine pancreas. $E M B O$ J. 5: $1477-1482$. 